\title{
Valuation of Defaultable Bonds and Debt Restructuring
}

\author{
Ariadna Dumitrescu* ${ }^{* \dagger}$ \\ Universitat Autònoma de Barcelona
}

First Version: September 2001

This Version: June 2003

\begin{abstract}
In this paper we develop a contingent valuation model for zero-coupon bonds with default. In order to emphasize the role of maturity time and place of the lender's claim in the hierarchy of debt of a firm, we consider a firm that issues two bonds with different maturities and different seniorage. The model allows us to analyze the implications of both debt renegotiation and capital structure of a firm on the prices of bonds. We obtain that renegotiation brings about a significant change in the bond prices and that the effect is dispersed through different channels: increasing the value of the firm, reallocating payments, and avoiding costly liquidation. Moreover, the presence of two creditors leads to qualitatively different implications for pricing, while emphasizing the importance of bond covenants and renegotiation of the entire debt.

JEL Classification numbers: G13, G32, G33. Keywords: Debt valuation, Defaultable bonds, Strategic contingent claim analysis, Modigliani-Miller theorem.
\end{abstract}

\footnotetext{
*I am very grateful to Jordi Caballé for his helpful comments and kind guidance. I would like to thank also Ron Anderson, Giacinta Cestone, David Pérez-Castrillo, an anonymous referee and seminar participants at Bank of England, ESADE Business School, Financial Markets Group/LSE, Haskayne School of Business, HEC Montreal, IDEA Microeconomics Workshop, IESE Business School, Said Business School, University College London, Universitat Pompeu Fabra, Credit 2002 Conference, Assesing the Risk of Corporate Default, 2002 European Economic Association Meeting, the 7th Meeting of Young Economists for their comments. All the remaining errors are my own responsability. Financial support from European Commision PHARE-ACE Programme, Grant P97-9177-S is gratefully acknowledged.

${ }^{\dagger}$ Correspondence address: Ariadna Dumitrescu, IDEA, Departament d'Economia i d'Història Econòmica, Universitat Autònoma de Barcelona, Edifici B, Bellaterra (Barcelona), 01893, Spain. Phone: (34) 935811561. Fax: (34) 935812 012. e-mail: adumit@idea.uab.es
} 


\section{Introduction}

In the recent years the work of Black and Scholes (1973) and Merton (1974) on option pricing has become an important tool in the valuation of corporate debt. The option-pricing approach has been used extensively in the valuation of stocks, bonds, convertible bonds and warrants. The theoretical insights of this approach are extremely useful, but unfortunately, the predictive power of this model has been widely challenged by the empirical tests. These empirical results signaled possible limitations of the model. Two of the most important limitations are the fact that default is assumed to occur only when the firm exhausts its assets and that the firm is assumed to have a simple capital structure.

The assumption of default occurring when the firm exhausts its assets was widely criticized. These critics lead to the conclusion that a credit valuation model has to provide a genuine representation of the relationship between the state of the firm and the events that might influence the deterioration of the firm value. Pursuing this goal, a new approach to credit valuation was introduced. This approach combines theory of bankruptcy and default with modern financial theory. The first to use this new approach were Leland (1994) and Leland and Toft (1996) who consider the design of optimal structure and the pricing of debt with credit risk. They allow bankruptcy to be determined endogenously and they also examine the pricing of bonds with arbitrary maturities. Later on, Anderson and Sundaresan (1996) explicitly describe the interaction between bondholders and shareholders. They obtain in this way an endogenous reorganization boundary and deviations from the absolute priority rule. Anderson, Sundaresan and Tychon (1996) extend the previous model from a discrete-time to a continuous-time model. Using this continuous-time setup they compute closed-form solutions and perform comparative statics. Mella-Barral and Perraudin (1997) also derive closed form solution for debt and equity modeling explicitly the shutdown condition for a firm. Fries, Miller and Perraudin (1997) price corporate debt in an industry with entry and exit of firms. Allowing for contract negotiation, Mella-Barral (1999) characterizes the dynamics of debt reorganization and endogenizes departures from the absolute priority rule. Fan and Sundaresan (2000) provide also a framework for debt renegotiation by endogenizing both the reorganization boundary and the optimal sharing rule between equity and debt holders upon default. Finally, Anderson and Sundaresan (2000) perform a comparison among the models of Merton (1974), Leland (1994), Anderson and Sundaresan (1996) and Mella-Barral and Perraudin (1997) showing that the models including endogenous bankruptcy are to some extent superior to Merton's model. 
A step forward in surmounting the limitation of a simple capital structure was made by Black and Cox (1976), who developed a model for pricing subordinate debt where both senior and junior debt have the same maturity. They follow Merton's approach (1974), in which risky debt is interpreted as a portfolio containing the safe assets and a short position in a put option written on the value of the firm's assets. Their junior debt could be seen as a portfolio comprising two calls: a long position in a call with a strike price equal to the face value of the senior bond and a short position in a call with a strike price equal to the sum of the face values of the two bonds.

The theory developed till now to overcome these limitations was concerned with the evaluation of credit status for securities with the same time of maturity and from the point of view of a particular lender. However, it is also important which are the maturity time and the place of the lender's claim in the hierarchy of the debt of a firm. It is not enough that the value of the firm is sufficient for paying the debt at its maturity. If the firm cannot fulfill the payment obligations at interim periods, than the payment of the debt that has later maturity will be affected. As a result, claims that have earlier maturity and are junior may trigger default and, therefore, bankruptcy.

In this paper we develop a contingent valuation model for zero-coupon bonds with different seniority and different maturity. We are interested in studying how renegotiation of debt and capital structure of the firm affect the prices of the bonds with default. Since the debt can be held by different bondholders we permit renegotiation in case of default on the early-maturity bond and this leads to strategic behaviour by bondholders. Incorporating strategic behaviour by bondholders in the valuation framework suggests that the presence of renegotiation possibilities when there are multiple creditors may lead to qualitatively different implications for pricing. Our approach is similar to the one of Anderson and Sundaresan (1996), but differs from it in two important points. First, we concentrate our attention on the effects of strategic behaviour of the bondholders only, the shareholders being in our model the residual claimants. Second, and more important, we consider the renegotiation of the entire amount of debt and not only on the cupon payment. This approach is used also by Christensen et al. (2002) in a single borrower setup, but the problem of renegotiating the entire amount of debt is reinforced in our case by the strategic behaviour of the two bondholders. The presence of two bondholders helps us also to emphasize the important role the bond covenants play in a firm with a reacher capital structure and when we allow for strategic behaviour of bondholders.

The remainder of this paper is organized as follows. Section 2 presents the basic valuation 
model. We describe directly the more complex model in which we allow for renegotiation. We present here the timing of the events, and the game that takes place between the bondholders in the case the firm is not able to honour its payments at date 1. Section 3 studies the equilibrium of the Bondholders' game. Section 4 proceeds with the valuation of the bonds. We compare the prices of the bonds in the model specified in Section 2, but also in two simpler models, the purpose of this comparison being to detect the effect on the price of bonds the capital structure of the firm and renegotiation bring about. Finally, Section 5 summarizes the results and gives some directions for further research.

\section{The Model}

There are three agents in our economy: two creditors (commercial banks, mutual or pension funds, etc.) and a firm - issuer of debt securities (corporation, commercial bank, government etc.). All three agents are risk neutral.

The creditors live for two periods and have different liquidity preference. We assume that the preferences of the two creditors are represented by the utility function $U_{\mathrm{i}}\left(c_{1}, c_{2}\right)=c_{1}+\delta_{\mathrm{i}} c_{2}$, where $c_{1}, c_{2}$ represent the consumption of the creditors in period 1 and 2 , respectively, and $\delta_{\mathrm{i}}$ represents creditor $i$ 's discount factor. To emphasize the fact that the creditors have different liquidity preferences, we assume that the discount factor is very small for the first creditor, and is very high for the second one. Consequently, the first creditor will prefer to consume in the first period and the second creditor will prefer to consume in the second period.

Consider now a simple situation in which the current liabilities of the firm are assumed to be 0 . Thus, the firm has a simple capital structure: equity and debt. Let us assume that markets are complete and frictionless, there are no taxes and the agents can borrow at the riskless interest rate $r$.

We assume that the firm owns a project and issues two zero coupon bonds and equity to raise funds meant to cover the financial needs of this project at date 0 . As a result, the initial investment in the project is equal to the total amount raised by issuing debt and equity. There is a junior bond with face value $D_{1}$ that matures at date 1 , and a senior bond with face value $D_{2}$ that is due to mature at date 2 . We assume that initial value of the firm is exogenous and equal to the total investment in the project. Since our economy is characterized by 0 corporate taxes, there is no distinction between the value of the assets of the firm and the value of the firm itself. 
This value is $V=E+B_{1}+B_{2}$, where $E$ is the value of equity, $B_{1}$ is the total market value of the junior corporate bond and $B_{2}$ is the total market value of the senior one. The project consists of a technology that transforms the initial investment in a random return. We model the technology as a binomial process: the value of the firm $V$ moves up to $V u$ with probability $p$ and down to $V d$ with probability $1-p$, where $u>1>d$. In what it follows we will denote by $V_{\mathrm{i}}$ the value of the firm at time $i$.

At date 0 the firm issues a short-term bond $B_{1}$ which is junior and a long-term debt $B_{2}$ which is senior. ${ }^{1}$ There are two covenants specified in the indenture of the senior bond: limitation on priority and cross-default. The limitation on priority provision restricts the shareholders to issue additional debt which may dilute the senior bondholder claim on the assets of the firm. In our case it requires that in the process of debt restructuring only junior bond can be issued. The cross-default provision specifies that the firm is in default when it fails to meet its obligations on any of its debt issues, that is in the case of default on the short-term debt, the senior debt becomes payable immediately.

Both bonds are subject to a positive probability of default. The existence of this positive default probability implies that the debt contracts should specify two contingency provisions: the lower reorganization boundary and the compensation to be received by the creditors when this lower reorganization boundary is reached.

The lower reorganization boundary represents the cut-off point where the liquid assets of the firm are not sufficient to meet the obligations of the debt contracts. When this cut-off point is reached, we say that financial distress takes place. As long as they meet the contractual obligations, shareholders have the residual control rights and debtholders cannot force liquidation. However, when the lower reorganization boundary is reached and, consequently, shareholders default on their debt contracts, the bondholders have a choice between allowing liquidation by court appointed trustee (Chapter 7 of U.S. Bankruptcy Code) or renegotiating the debt contracts. In the case of liquidation the firm sells its assets, pays a liquidation cost and what is left is allocated between bondholders. In the case bondholders choose to renegotiate the debt, this can be done either out of court (workout) or in court (Chapter 11 of U.S. Bankruptcy Code). Since we do not intend to model the shareholders specifically and in case of default the control of the firm is transferred from stockholders to bondholders, our renegotiation procedure will

\footnotetext{
${ }^{1}$ The assumption is without loss of generality and is ment to illustrate the point that junior bond with earlier maturity can trigger default on the long-term, senior bond. The case when the short-term bond is senior and the long-term bond is junior is similar with Black and Cox (1976) and it will not involve debt renegotiation.
} 
mirror the restructuring through out-of-court arrangements. ${ }^{2}$

A very important assumption of our model is that the compensation received by bondholders after bankruptcy follows the absolute priority rule. According to this absolute priority rule the payments to debtholders should be made before any payment is made to shareholders. Also, the payments of the debtholders are made such that the senior claim payments should be always made before any payments are made to the junior claims. We also assume that in case of default of the debt contracts the debtholders can use the assets without any loss of value (except the liquidation costs).

\subsection{Time Structure}

We set up the model in discrete time because it allows the modeling of the bankruptcy process to be more transparent. The sequence of events is the following:

Date 0: The firm issues both short-term and long-term debt $B_{1}$ and $B_{2}$, respectively. The promised final payments are $D_{1}$ and $D_{2}$, respectively. Creditor 1 buys the bond $B_{1}$ and Creditor 2 buys the bond $B_{2}$.

Date 1: Maturity date of bond $B_{1}$. The stockholders pay off the Bondholder 1 if they can. If they cannot, the ownership of the firm passes to the bondholders. The bondholders decide if the firm enters a liquidation or a restructuring process. In case of liquidation, the firm pays the liquidation costs $L$ and then the bondholders are paid according to the absolute priority rule. In case of restructuring, the firm either changes the maturity of junior debt at $t=2$, or issues new debt with maturity at $t=2$. We assume that there is a cost of restructuring $K$ and this cost is smaller than the cost of liquidation $L$ (more precisely, we assume that $K<\frac{r}{1+r} L$, and $\left.L<V_{0} d\right) .^{3}$

Date 2: Maturity date of bond $B_{2}$. Conditional on the fact that the firm did not get bankrupt in the previous period, the stockholders pay off the bondholders if they can. If they cannot, the firm enters in a liquidation process. The control of the firm is transferred from stockholders to the bondholders. The firm is liquidated and the bondholders are paid according to the absolute priority rule.

\footnotetext{
${ }^{2}$ According to Gilson et al. (1990), almost 50\% of the companies in financial distress avoid liquidation through out-of-court debt restructuring. The advantage of this procedure is that workouts are usually a lot less expensive than Chapter 11 bankruptcy procedure.

${ }^{3}$ Empirical studies show that the costs of debt restructuring are significantly lower than the costs of liquidation.
} 


\subsection{The Game}

At date 1 , the value of the firm is $V_{1}$. The payment obligation of the firm at this moment amounts to $D_{1}$. If the value of the firm $V_{1}$ exceeds $D_{1}$, the stockholders honour the debt obligation by selling out assets that amount to $D_{1}$. Otherwise, the firm defaults and the stockholders give up the control in favour of bondholders. Once the firm defaults on one of its payments all the creditors have the right to demand information, and therefore they discover the value of the firm at date $1, V_{1}$. If the value of the firm following restructuring, $V_{2}^{*}$, is expected to be very low ( i.e. $E\left[V_{2}^{*}\right] \leq D_{2}$ ) both bondholders realize that issuing additional debt will not make them better off. Due to the existence of the senior bond covenant, the debt issued at date 1 has to be junior to the debt $B_{2}$ and therefore, the expected payment to this newly issued debt will be zero, no bondholder being willing to buy this debt. If the value of the firm is such that $E\left[V_{2}^{*}\right]>D_{2}$, the bondholders choose between liquidating and rescuing the firm. We consider the case when unanimity it not necessarily for the reorganization to be approved (see Franks and Torous (1989)). Consequently, liquidation occurs only when both bondholders are taking this decision. In the case of liquidation, the assets of the firm are sold and the payments are made to the bondholders. If one of the bondholders wants to rescue the firm, then the debt will be restructured independently of the other's action. There are different ways to restructure the debt: reducing the principal obligations, increasing maturity of the debt or accepting equity of the firm. We assume that the Bondholder 1 restructures the debt by increasing the maturity of the debt. On the other hand, if the Bondholder 2 wants to prevent liquidation he can do so only if the firm issues new debt. ${ }^{4}$ The restructuring of the debt can be done only if the firm pays a cost $K$, which, for simplicity, we assume that it is the same in both cases.

Let us see now what happens at date 2. The situation is very similar, but the allocation of payments depends on what happened at date 1 . First, if the payments for the bond $B_{1}$ where made at date 1 , the only payment left to be honoured at date 2 is the senior bond $B_{2}$. In this case the value of the firm becomes $F_{1}=V_{1}-D_{1}$. Therefore, if the value of the firm at time 2 , that is $\mathbb{F}_{2}$, exceeds the payment obligation $D_{2}$, the stockholders honour the debt obligation. Otherwise, they will liquidate the firm and obtain the assets' value $\boldsymbol{F}_{2}$ net of liquidation cost. In the case the firm honoured its payment at date 1 , we have to take into account that for doing

\footnotetext{
${ }^{4}$ It does not pay for an outsider to undertake restructuring since the value of the firm is small, $V_{1}<D_{1}$. If a new creditor is willing to invest $D_{1}$, the value of the firm at date 2 will be in expected terms $\left(V_{1}-K\right)(1+r)$ which is smaller than $D_{1}(1+r)$, the amount that should be paid to the new investor. Moreover, the new issued debt has always lower seniorage than the existent debt so he will be paid only after the senior debt is paid.
} 
so the firm is liquidating a part of its assets equal to $D_{1}$, and the value of the firm decreases therefore by this amount $\boldsymbol{F}_{1}=V_{1}-D_{1}$.

Second, if at date 1 we had default on the obligation, three possible cases might occur: liquidation, rescue by Bondholder 1, and rescue by Bondholder 2. If liquidation takes place at date 1, the game is already over. The firm sells out the assets, pays a liquidation $\operatorname{cost} L$ and makes the paym/2nts according/to the priority rule. Bondholder 1 owns the senion/2ond and he will sqceive $\min V_{1}-L, \frac{D_{2}}{1+r}$. Bondholder 2 will receive what is left, i.e. $\max \quad V_{1}-\frac{D_{2}}{1+r}-L, 0$.

When restructuring takes places, the firm is paying the restructuring cost $K$, and thus, the value of the firm becomes $V_{1}^{*}=V_{1}-K$. If the restructuring of the firm is made by Bondholder 1 , at date 2 he will be entitled to a payment $D_{1}^{\prime}$ which is junior to $D_{2}$. If the value of the firm at date $2, V_{2}^{*}$ exceeds the total payment obligation $D_{1}^{\prime}+D_{2}$, the stockholders honour the debt obligation. Otherwise, the Bondholder 1 will receive $\max \left\{0, V_{2}^{*}-D_{2}\right\}$ and Bondholder 2 will receive $\min \left\{V_{2}^{*}, D_{2}\right\}$. If the firm is in default at date 2 , we have to subtract the liquidation cost from these payoffs. In order to keep it simple at this point we will write the exact formula for these payoffs later on. Finally, if the rescue of the firm was made by Bondholder 2, at date 2 the Bondholder 2 will own two bonds and he will be entitled to a payment of $D_{1}^{\prime \prime}+D_{2}$. The payment he receives depends again on the realization of $V_{2}^{*}$ and it is $\min \left\{D_{1}^{\prime \prime}+D_{2}, V_{2}^{*}\right\}$.

When the Bondholder 2 is willing to pay the debt, the firm will issue new debt which amounts to $D_{1}$. If Bondholder 2 is the only one to rescue the ffrm, the Bondholdes 14 will receive exactly the amount he received in case of liquidation $\max V_{1 / 4}-\frac{D_{2}}{1+r}-L, 0$, the amount $D_{1}-\max \quad V_{1}-\frac{D_{2}}{1+r}-L, 0$ being used for increasing the value of the firm. Hence, the value of the firm will be in this case $V_{1}^{* *}=V_{1}+D_{1}-K-\max V_{1}-\frac{D_{2}}{1+r}-L, 0^{3 / 4}$. Finally, in the case both bondholders are willing to rescue the firm, the firm will accept both offers, the new value of the firm becoming in this case $V_{1}^{* * *}=V_{1}+D_{1}-2 K$. The firm will postpone the debt due to Bondholder 1 by changing the face value of the debt to $D_{1}^{\prime}$ and also by issuing new debt with face value $D_{1}^{\prime \prime}$. The two new types of debt are junior to the debt $B_{2}$ and they have the same seniority.

The payments made at date 2 in the case of restructuring for the new debt $D_{1}^{\prime}$ and $D_{2}^{\prime \prime}$ are chosen such that there exist no arbitrage opportunities between the first and second period. 


\section{The Equilibrium of the Bondholders' Game}

We study now the case when the firm is not able to meet its payment obligation at date 1 , i.e. $V_{1}<D_{1}$, but the value of the firm is still high enough to allow for restructuring, meaning $E\left[V_{2}^{*}\right] \geq D_{2}$. This can be written equivalently as

$$
V_{1}-K \geq \frac{D_{2}}{p u+(1-p) d}
$$

Let us define $\bar{V}$ as

$$
\bar{V}=\frac{D_{2}}{p u+(1-p) d}+K \text {. }
$$

As we have already explained, the ownership of the firm passes into the hands of the bondholders and they decide whether to rescue or to liquidate the firm. We assume that the bondholders have complete information, the game is common knowledge, and that they act in their own interest. Moreover, at the beginning of the game, they can observe the realization of the firm value, $V_{1}$.

Equilibrium in the bondholders' game consists of the actions of the bondholders that constitute the best response. When making the decision the bondholders have to take into consideration both current period payoff and continuation payoff.

In order to characterize the solution we need to specify the following notations. The actions of Bondholder 1 are $\left\{L_{1}, R_{1}\right\}$ and the actions of Bondholder 2 are $\left\{L_{2}, R_{2}\right\}$, where $L_{\mathrm{i}}$ means that bondholder $i$ chooses to liquidate the firm and $R_{\mathrm{i}}$ means that the bondholder $i$ chooses to restructure the firm.

Proposition 1 In the equilibrium Bondholder 1 chooses to restructure, $R_{1}$, and Bondholder 2 chooses to liquidate, $L_{1}$.

The capital structure of the firm and the covenants of the senior debt play a very important role in our model. While the cross-default provision brings about the renegotiation of the debt contracts, the limitation on priority drives the equilibrium of the bondholders game. As we have seen already the value of the firm is utmost when both bondholders are willing to restructure the firm. The Pareto efficient equilibrium consists of bondholders restructuring and invigorate thus the firm through their action. However, in equilibrium Bondholder 2 chooses to liquidate. The grounds of his decision comes from the fact that his overall position in the hierarchy of debt is downgraded. At the beginning he had a senior bond. If both bondholders undertake restructuring Bondholder 2 will have a senior bond as before but also a junior bond. This last 
bond has actually the same seniority as the seniority of the bond owned by Bondholder 1 and therefore the payments on these two junior bonds will be made at once. Therefore, the payments of the Bondholder 2 are reduced and in consequence he chooses to liquidate the firm.

There are also two other important issues to be taken into account when solving for the equilibrium: Bondholder 1 owns a junior debt and default occurs when the value of the firm is very small. First, Bondholder 1 owns a junior debt and he receives his payment after the senior bond payment is made. Therefore, the smaller the value of the firm, the smaller the amount that is left after senior bond payment. As a result, his best response to any of Bondholder 2 actions is to restructure and increase the value of the firm. Thus, if Bondholder 2 wants to liquidate, Bondholder 1 is obviously better off by restructuring since restructuring gives him at least as high equal expected payoff. This happens because the bondholder will never undertake restructuring when the expected payoff is smaller than the present value of the debt (see the non-arbitrage condition). If Bondholder 2 wants to rescue, Bondholder 1 is gaining even more because the value of the firm is increased more by the participation of Bondholder 2, but the newly issued debt for both bondholders has the same seniority.

Second, default occurs when the value of the firm is small. Since Bondholder 2 knows that and owns a senior bond, it does not pay for him to reinvest and accumulate debt. He prefers to leave Bondholder 1 to rescue the firm. As a result, Bondholder 2's best response to $R_{1}$ is $L_{2}$. In the case the value of the firm net of liquidation costs is still high enough to cover the debt due to him $\frac{D_{2}}{1+r}$, we have that the best response of Bondholder 2 when Bondholder 1 chooses to liquidate is to liquidate. We also obtain that, for some small values of the parameters, the best response to $L_{1}$ is to restructure. However, for these values we have already argued that the bondholders are not going to invest and accumulate more debt because if they do, they are going to lose. Under these circumstances, we can conclude that the equilibrium of the game is $\left(R_{1}, L_{2}\right)$.

Corollary 2 The equilibrium of the bondholders' game is preserved even when $K=L=0$.

If we substitute the parameters $K=L=0$ in the proof of Proposition 1, the proof is still valid. The corollary emphasizes the fact that the equilibrium of the bondholders' game is driven by the capital structure of the firm (and the presence of covenants) and not by liquidation costs. This happens again only for the values of the parameters for which restructuring makes sense, i.e. in this case $V_{1} \geq \frac{D_{2}}{p u+(1-p) d}$.

Once the bondholders announced their decisions, the shareholders are compelled to follow 
the decisions of the bondholders. They play a passive role since the ownership was already conceded to the bondholders. Since the cost associated with the restructuring process is the same, independent of who is restructuring the firm, the shareholders are indifferent between changing the maturity of bond $B_{1}$ at $t=2$ and issuing new debt.

\section{The Valuation of the Bonds}

In order to price a bond we have to compute the present value of the expected bond payments. The prices of the bonds are influenced by the characteristics of the project to be undertaken but also by the structure of the firm. We focus on determining the lower reorganization boundary and the compensation to be received by bondholders and shareholders. Once we know the payments received by every agent, we can compute the prices at date 0 for the two bonds and equity by computing the net present value of future payments. We will determine the prices of the bonds in three different setups and compare the corresponding prices.

First, we will compute the prices of the two bonds in the model we presented above. We are interested in finding out how introducing debt renegotiation will affect the value of the bonds. For this purpose, we will compare the prices we obtained, $B_{1}$ and $B_{2}$ with the prices of two similar bonds (the same maturity date and the same debt face value) $B_{1}^{\prime \prime}$ and $B_{2}^{\prime \prime}$. The bonds $B_{1}^{\prime \prime}$ and $B_{2}^{\prime \prime}$ are issued by a firm with a similar capital structure, but in which the bondholders are not allowed to restructure the firm in case of default.

We will see that changes in the characteristics of the project (which can be seen as caused by changes in the credit quality of the issuer) are inducing different bond prices. However, it is not the case that only the characteristics of the project are influencing the valuation of the bonds. The prices of the bonds can also be influenced by the presence of other bonds with different maturity or different seniority. To isolate this effect we compare the prices of the short-term bond $B_{1}^{\prime \prime}$ with the price of a short-term bond $B_{1}^{\prime}$ and the price of the long-term bond $B_{2}^{\prime \prime}$ with the price of a long-term bond $B_{2}^{\prime}$. The bonds $B_{1}^{\prime}$ and $B_{2}^{\prime}$ are bonds with similar face value to $B_{1}^{\prime \prime}$ and $B_{2}^{\prime \prime}$ and each of them is a bond in a firm where this is the only debt outstanding.

Before proceeding with the valuation, let us first determine the equilibrium market interest rate. We assume that the firm that owns the project $V_{0}$ is financed completely with equity. We determine the interest rate from the following non-arbitrage condition: an investor should be indifferent between investing in equity in the firm fully financed by equity or in a riskless asset. On the one hand, the expected payoff from investing $\$ 1$ in equity is the total expected payment 
of the project divided by the value of equity $q$, i.e. $\frac{p V_{0} u+(1-p) V_{0} d}{q}$. Since the firm is financed fully with equity, we obtain that $q=V_{0}$, and therefore, the expected payoff from investing $\$ 1$ in equity is $p u+(1-p) d$. On the other, the expected payment from investing $\$ 1$ in the riskless asset is $1+r$. As a result, our non-arbitrage condition, becomes $p u+(1-p) d=1+r$.

\subsection{Valuation for $B_{1}$ and $B_{2}$}

As we already mentioned in the presentation of the model, the payments in the case of restructuring have to be such that there are no arbitrage opportunities. First, the Bondholder 1 should be indifferent between the payment he is entitled to receive this period, $D_{1}$ and the expected payment he will obtain next period if he decides to postpone the maturity of the bond $D_{1}^{\prime}{ }^{5}$ Thus, we have $D_{1}=\frac{1}{1+r} E_{1}\left[\min \left\{V_{2}^{*}-D_{2}, D_{1}^{\prime}\right\}\right]$, where as explained above, $V_{1}^{*}=V_{1}-K$. Second, the Bondholder 2 should be indifferent between rescuing the firm by paying $D_{1}$ at date 1 and receiving $D_{1}^{\prime \prime}$ next period. However, he is aware of the1 fact that if he resspuctures the firm, its value at date 1 will increase at least $\underset{1 / 2}{\text { by }} \underset{4}{1 / 2} D_{1}-\max V_{1}-\frac{D_{2}}{1+r}-L, 0$. If we define $V_{1}^{* *}=V_{1}-K+D_{1}-\max \quad V_{1}-\frac{D_{2}}{1+r}-L, 0 \quad$, we can write the arbitrage condition $D_{1}=\frac{1}{1+r} E_{1}\left[\min \left\{V_{2}^{* *}-D_{2}, D_{1}^{\prime \prime}\right\}\right]$.

The price of the two bonds will depend critically on the relationship between the two debt face values $D_{1}$ and $D_{2}$.

Remark 1 In case of default none of the bondholders will be willing to rescue the firm if $D_{1}<\frac{D_{2}}{p u+(1-p) d}+K \equiv \bar{V}$.

In case of default we have $V_{1} \leq D_{1}$. However, the bondholders are willing to rescue the firm only if $V_{1} \geq \bar{V}$. Since $V_{1} \leq D_{1}<\bar{V}$, although we allow the bondholders to renegotiate they will not be willing to restructure the firm. Hence, the value of the bonds and equity will be the same as in the case when we do not allow for renegotiation. Therefore, the interesting case for our analysis is the case when $D_{1} \geq \bar{V}$. While looking at the effects of debt renegotiation on the prices of bonds we will concentrate our attention only on this case because this is the case when the strategic behaviour of bondholders might lead to restructuring.

However, when $\bar{V} \leq D_{1}$ we will have both cases when the bondholders are willing to restructure and cases when they are not. Thus, if $V_{1} \leq \bar{V}$ the bondholders will not be willing to

\footnotetext{
${ }^{5}$ The bondholder is choosing exactly the quantity that makes him indifferent. He will never choose a larger amount because by doing so either he receives $V_{2}^{*}-D_{2}$ or an arbitrage opportunity exists.
} 
rescue the firm since for these values of $V_{1}$ the expected value of the firm is less than $D_{2}$, the face value of debt due to Bondholder 2 at date 2. Since the debt issued at date 1 is junior to debt $D_{2}$ of Bondholder 2, the expected payment is 0 , and none of the creditors is willing to buy this debt. If $\bar{V} \leq V_{1} \leq D_{1}$, the expected payment to the newly issued debt is positive and the bondholders play the game described above. The payoffs of the two bondholders (and therefore, the valuation formula of the bonds) depend both on the face values of the debt and on the initial value $V_{0}$.

In the case when $D_{1} \geq \bar{V}$, the strategic behaviour of the bondholders affects the payoffs of the bonds at date 1 , and thus, the valuation formula is changed. In this case liquidation occurs for values of the firm smaller than a new threshold $\bar{V}=\frac{D_{2}}{p u+(1-p) d}+K$, this threshold being smaller than the threshold we had before $\left(D_{1}\right)$. If $V_{1} \leq \bar{V}$, we have default; the firm liquid/2tes its assets and/4he bondholders share the payments. The pazyoff of Bondhoglder 1 is $\max V_{1}-L-\frac{D_{2}}{1+r}, 0$, while the payoff of Bondholder 2 is $\min V_{1}-L, \frac{D_{2}}{1+r}$. If $\bar{V} \leq V_{1}<D_{1}$, the firm is not able to honour its debt obligation, but it is not liquidated. In this case, the bondholders decide to restructure the debt. In equilibrium, Bondholder 1 rescues the firm by postponing its debt maturity till date 2, the payoffs of the two bondholders being $\frac{1}{1+r} E_{1} \max \left\{0, \min \left\{V_{2}^{*}-D_{2}, D_{1}^{\prime}\right\}-L \cdot I_{\left\{\mathrm{V}_{1} \mid \mathrm{D}_{2}<\mathrm{V}_{2}^{*}<\mathrm{D}_{2}+\mathrm{D}_{1}^{\prime}\right\}}\left(V_{1}\right)\right\}$ for Bondholder 1 and $\frac{1}{1+r} E_{1}\left[\min \left\{V_{2}^{*}-L, D_{2}\right\}\right]$ for Bondholder 2. In case the firm does not default at date 1 the payoff of Bondholder 1 is $D_{1}$. The Bondholder 2 waits till date 2, the maturity date of its debt, and he receives then $\min \left\{D_{2}, D_{2}\right\}-L \cdot I_{\left\{\nabla_{2} \mid b_{2}<D_{2}\right\}}\left(D_{2}\right)$. He receives the entitled debt $D_{2}$ if the value of the debt is smaller than the value of the firm. Otherwise, he receives the value of the firm net of liquidation costs.

As we can see in Figure 1 the price of the short-term bond is increasing in $V_{0}$. There are two kinks in the price function. The first one is the result of the upper state value of the firm becoming higher than the face value of the short-term debt $D_{1}$ (in our example when $V_{0}=5$ ) and the second when also the lower state value of the firm exceeds this amount $\left(V_{0}=20\right)$. However, the price of long-term debt is not anymore an increasing function of $V_{0}$. When the value of the firm becomes higher than the face value of the short-term debt $D_{1}$, the firm is selling off assets amounting to $D_{1}$, and therefore, the value of the firm is decreasing. Consequently, for these values of $V_{0}$ we detect a sharp decrease in the price of the long term bond.

The price of equity is computed in the same manner. According to the priority rule the equity owners are the last ones to be paid. So, if we had default at date 1 they would receive 

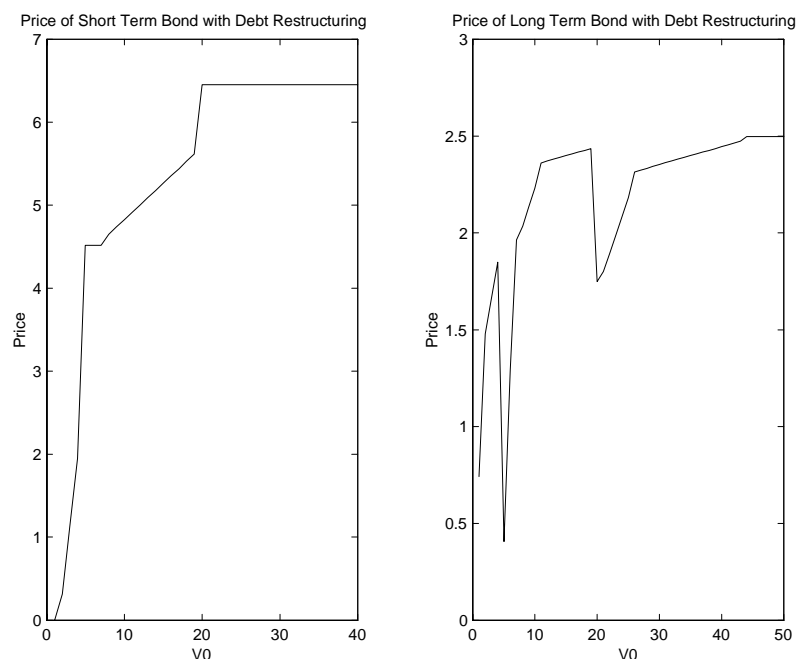

Figure 1: Prices of the short-term bond and the long-term bond when debt restructuring is allowed. The values of parameters are: $D_{1}=10, D_{2}=6, K=0.4, L=0.02$, $p=0.7, u=2, d=0.5$.

nothing. Then, if the value of parameters still allows for restructuring, we have two cases. First, if after restructuring we have default at date 2, the equity owners will be left with nothing. Secondly, if we do not have default at date 2, they will receive the value of the firm net of the payments due to the two bondholders $V_{2}^{*}-D_{1}^{\prime}-D_{2}$. If we did not have default at date 1 , the equity owners would receive the value of the firm minus the payment to the Bondholder 2. Thus, if we reach the date 2 , the equity owners will receive nothing in case we have default at date 2 , and $\boldsymbol{F}_{2}-D_{2}$ in case we do not have default at date 2 . Once we have found the valuation formula for the two bonds and for equity, we can also compute the value of the firm $V$ and we notice that we do not obtain the initial value of the project because we have to subtract liquidation and restructuring costs. As expected, in the case where we have these costs the Modigliani-Miller theorem does not hold good. Since in our model we allow for renegotiation, we want to see if this assumption jeopardizes the accomplishment of Modigliani-Miller theorem. For that we assume that the restructuring and liquidation costs are zero, so we can eliminate their disturbing effect. Once all the other assumptions of Modigliani-Miller theorem are fulfilled, we see what happens in our model. The first step is to determine how the behaviour of the agents changes when we set $K=L=0$. As we already stated in the Corollary 2, the equilibrium of bondholders game is the same when we set $K=L=0$. Consequently, the payoffs of the two bondholders are exactly 
the same, except that we substitute $K=L=0$ in the respective formulas. Since renegotiation does not involve any dissipative cost and the outcome of the project is divided between the agents, we obtain the following result:

Lemma 1 If $K=L=0$, the Modigliani-Miller theorem holds even when renegotiation is permitted.

We obtain, hence, that the value of the firm remains the same even when we allow for renegotiation. The allocation of the payoffs is different when we allow renegotiation, but in the absence of liquidation and restructuring costs the value of the firm is unchanged. However, we will see later that the presence of renegotiation will offset the effect of liquidation and restructuring costs on the value of the firm when $\frac{r}{1+r} L>K>0$.

\subsection{Valuation for $\mathrm{B}_{1}^{\prime}$ and $\mathrm{B}_{2}^{\prime}$}

As shown above, the payments of the two bonds, and therefore, the values of the bonds depend on the face values of the debt and on the initial value $V_{0}$. Let us consider now the following two cases of a similar firm (with a similar project) but with a different capital structure. First, we consider a firm with only one outstanding bond, a bond with maturity date at $t=1$ and with face value $D_{1}$ and equity $E^{\prime}$. Second, we consider the case of a firm with only one bond outstanding, a bond with maturity date 2 and with face value $D_{2}$ and equity $E^{\prime \prime}$.

If we assume that at date 1 the only outstanding debt is $B_{1}^{\prime}$, the cash flow depends only on the realization of the value of the firm $V_{1}$. If the value of the firms is high enough to pay the debt, $V_{1} \geq D_{1}$, the bondholder receives what he is entitled to (i.e. $D_{1}$ ). Otherwise, he receives the amount that results from liquidating the firm. Since we assume that liquidation is costly, in the case $V_{1} \leq D_{1}$ we have to subtract from the value of the firm the liquidation cost $L$. We have also computed the price of equity. As expected, the shareholders obtain nothing in case of default at date 1 and they receive $V_{1}-D_{1}$ in case of non-default.

We consider now the second case where the firm issues a bond with maturity date 2 and with face value $D_{2}$ and it issues equity $E^{\prime \prime}$. When the only outstanding debt is $B_{2}^{\prime}$ at date 2, we are interested only if the value of the firm at $t=2, V_{2}$, is high enough to pay the debt. If this is the case, i.e. $V_{2} \geq D_{2}$, the bondholder receives what he is entitled to (i.e., $D_{2}$ ). Otherwise, he receives the amount that results from liquidating the firm $V_{2}-L$. Similarly to the previous case, we find the price of equity. In case of default, the shareholders do not receive anything. 
Otherwise, they receive what is left after the payment is done to the bondholder who owns $B_{2}^{\prime \prime}, V_{2}-D_{2}$.

\subsection{Valuation for $B_{1}^{\prime \prime}$ and $B_{2}^{\prime \prime}$}

We consider now a firm with the following capital structure: equity, a zero-coupon bond $B_{1}^{\prime \prime}$ with maturity date $t=1$ and face value $D_{1}$, and a zero-coupon bond $B_{2}^{\prime \prime}$ with maturity date $t=2$ and face value $D_{2}$. However, we assume now that the bondholders are not able to rescue the firm in case of default at date 1 . We obtain the prices for the two bonds $B_{1}^{\prime \prime}$ and $B_{2}^{\prime \prime}$ in a similar manner to the case when we do allow for debt restructuring.

If $V_{1} \leq D_{1}$, we have default on the junior debt at date 1 . Since we do not allow the bondholders to rescue the firm, the default at date 1 will trigger liquidation. The firm sells its assets, pays the liquidation costs $L$ and then the bondhod/fers are paid according to the priority rule. The payoff of Bondholder 2 is $\min V_{1}-L, \frac{D_{2}}{1+r}$. He is the first one to be paid since his depht is senior to the/debt owned by Bondholder 1. Bondholder 1 receives what is left, i.e. $\max V_{1}-L-\frac{D_{2}}{1+r}, 0$. In case the firm does not default at date 1 the payoff of Bondholder 1 is $D_{1}$. The value of the firm decreases by this amount and becomes $V_{1}=V_{1}-D_{1}$. Bondholder 2 waits till date 2 , the maturity date of its debt. If the value of the debt is smaller than the value of the firm, he will receive the entitled debt $D_{2}$. Otherwise, he receives the value of the firm net of liquidation costs $b_{2}-L$. Again, since equity owners are the last ones to receive their payments (according to priority rule), in case of default at date 1 they do not receive anything. Then, if default does not occur at date 1, they will receive at date 2 what is left after payment is made to Bondholder 2. They do not receive anything in case of default at date 2, and they receive $\boldsymbol{F}_{2}-\min \left\{\boldsymbol{F}_{2}, D_{2}\right\}$ in case of non-default.

If we compare the values of the firm we obtained in the two cases (with and without restructuring), we notice that for the parameters values for which restructuring takes place $\left(\bar{V}<V_{1} \leq\right.$ $\left.D_{1}\right)$ the value of the firm changes from $V_{1}-L$ to $\frac{1}{1+r} E_{1} \quad V_{2}^{*}-L \cdot I_{\left\{\mathrm{V}_{2}^{*} \mid \mathrm{V}_{2}^{*} \leq \mathrm{D}_{2}+\mathrm{D}_{1}^{\prime}\right\}}\left(V_{2}^{*}\right)$. We assumed that $K<\frac{r}{1+r} L$ which implies $V_{1}-L<\left(V_{1}-K\right)-\frac{1}{1+r} E_{1} L \cdot I_{\left\{\mathrm{V}_{2}^{*} \mid \mathrm{V}_{2}^{*} \leq \mathrm{D}_{2}+\mathrm{D}_{1}^{\prime}\right\}}\left(V_{2}^{*}\right)$. It is interesting to notice that if the liquidation and bankruptcy costs are different from 0 , the strategic behaviour induces a change in the value of firm, and therefore, it has an offsetting effect in the violation of the Modigliani-Miller theorem.

In computing the prices we use the interest rate to discount the payments received. To perform the comparison we need to see if the interest rate is indeed the same in all the cases. 
We compare the equilibrium interest rate in the case of a firm financed entirely by equity with our two cases when the firm is financed by equity, short-term debt and long-term debt and we allow or not for renegotiation. As the following lemma shows, since the bondholders and shareholders are building their expectations rationally, neither the different structure of the firm nor the presence of renegotiation changes the equilibrium interest rate.

Lemma 2 If the firm is financed by equity, short-term debt and long-term debt, the interest rate still satisfies $p u+(1-p) d=1+r$ independently of the fact that we allow for renegotiation or not.

\subsection{Price Comparison}

Let us consider now the two cases of the firm with the same capital structure: a short-term bond, a long-term bond and equity, the difference lies in the fact that we allow or not for restructuring in case of default. We compare the prices of the two short-term bonds $B_{1}$ and $B_{1}^{\prime \prime}$ and of the two long-term bonds $B_{2}$ and $B_{2}^{\prime \prime}$, respectively.

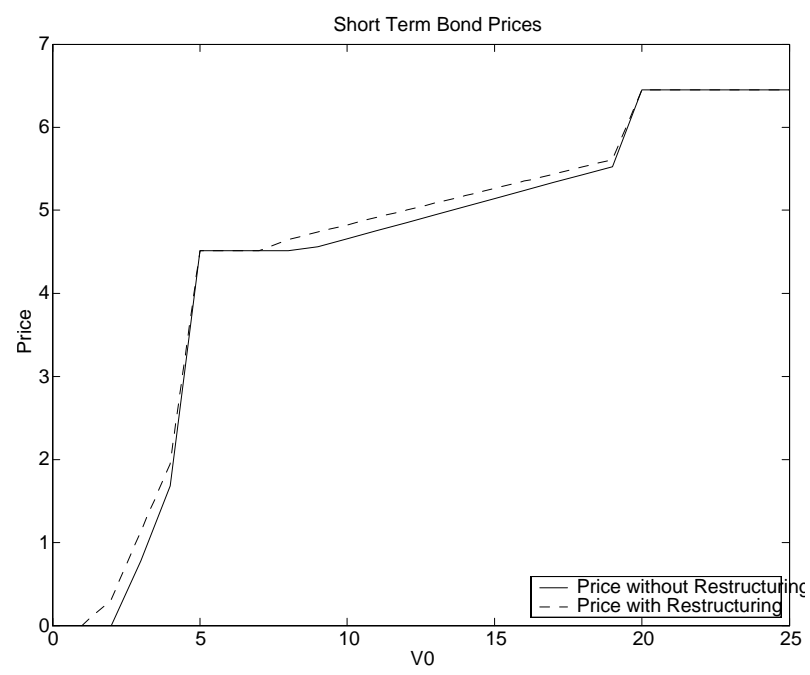

Figure 2: Comparison of the short-term prices. The values of parameters are: $D_{1}=10$, $D_{2}=6, K=0.4, L=0.02, p=0.7, u=2, d=0.5$.

When deriving the equilibrium of the game we obtained that the Bondholder 1 is better off undertaking restructuring independently of the action of the Bondholder 2. Since in equilibrium the Bondholder 1 chooses to restructure, it is obvious that his payoff has to be higher when restructuring takes place than when liquidation occurs. Moreover, by restructuring he postpones 
or avoids costly liquidation giving the firm the possibility to recover. As a result, we obtain that his expected payments are higher and consequently, that the price at date 0 of the short-term bond is higher if strategic interaction between bondholders is allowed.

In Figure 2 we see that there are two ranges for $V_{0}$ where the price of the short-term bond is higher in the case we allow for debt restructuring. The values of $V_{0}$ for which this happens are exactly the two possible cases when the value of the firm is lower than $D_{1}$ but higher than $\bar{V}$. Since the price of the short-term bond is higher we have a decrease in the spread of short-term bond when strategic behaviour is allowed.

However, the equilibrium payoff of the Bondholder 2 is lower than in the case both bondholders liquidate. Since the best response of the Bondholder 1 is to restructure when Bondholder 2 liquidates, liquidation by both bondholders will not be an equilibrium for $V_{1}>\bar{V}$. So, Bondholder 2 ends up with a payoff lower than in the case we do not allow for debt restructuring. Since in the case we allow for restructuring the expected payoffs are smaller, we will have also that the price at date 0 of the long-term bond is smaller and consequently, the spread is higher. Similarly to the case of short-term bond prices we have two regions where price differ. This can be easily seen in the Figure 3.

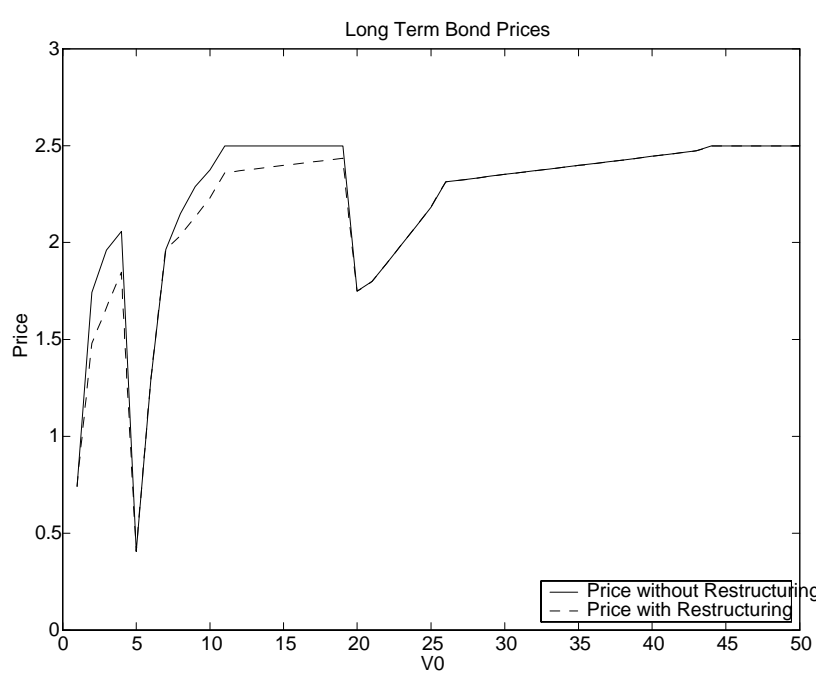

Figure 3: Comparison of the long-term prices. The values of parameters are: $D_{1}=10$, $D_{2}=6, K=0.4, L=0.02, p=0.7, u=2, d=0.5$.

As we have already explained, the bondholders' payoffs are significantly changed when we allow for debt restructuring. However, this is not the only issue here. We are interested to see 
how the presence of strategic behaviour is reflected in the payments, and consequently, in the prices of bonds, but also to understand what lies behind these changes. Thus, there are different channels in which strategic behaviour comes into play: through the change in the value of the firm, through the reallocation of payments, through the possible changes in the hierarchy of debt or avoiding costly liquidation.

We should also emphasize that in our models the bankruptcy and restructuring costs are anticipated by the bondholders and therefore, they are incorporated in prices. The same happens with the bankruptcy procedure. In the case when the bondholders do not restructure the debt, the bankruptcy code predicts liquidation similar to Chapter 7 of U.S. Bankruptcy Code. Our model suggests thus, that the prices of the bonds are also affected by the bankruptcy procedure.

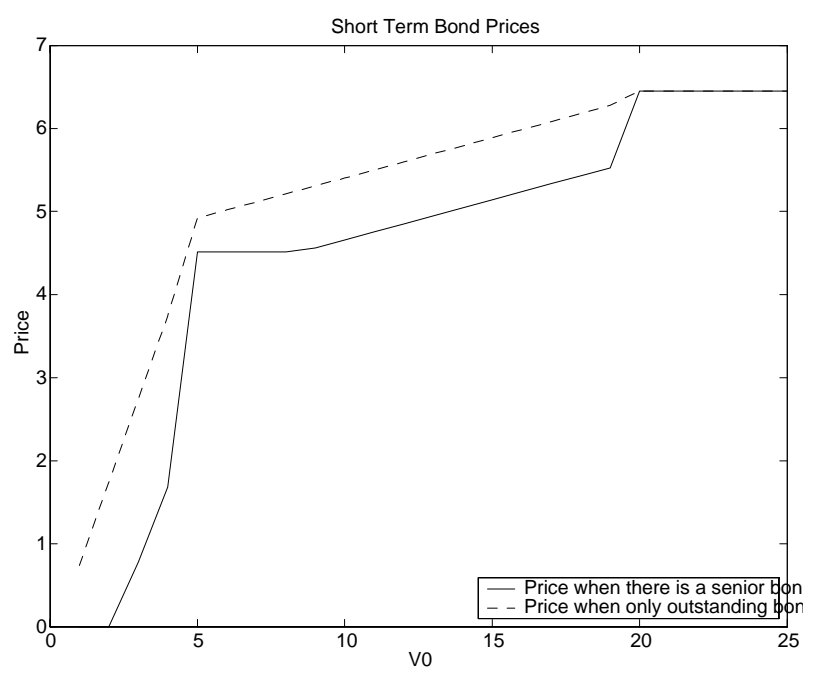

Figure 4: Comparison of the short-term prices in two firms with different capital structure. The values of parameters are: $D_{1}=10, D_{2}=6, K=0.4, L=0.02, p=0.7$, $u=2, d=0.5$

Consider finally, the short-term bonds $B_{1}^{\prime \prime}$ and $B_{1}^{\prime}$. As we have already explained, the two bonds have the same face value $D_{1}$ and maturity date 1 . Their difference lies in the fact that they are outstanding bonds in firms with different capital structure. We compare the two prices and we obtain that the short-term bond has a higher price when this is the only outstanding bond. The result is very intuitive. Since in case of default the payments are made according to the priority rule, the price of a junior bond is influenced by the presence of another, senior bond. In case of default, the owner of the bond $B_{1}^{\prime}$ is paid immediately after the liquidation 


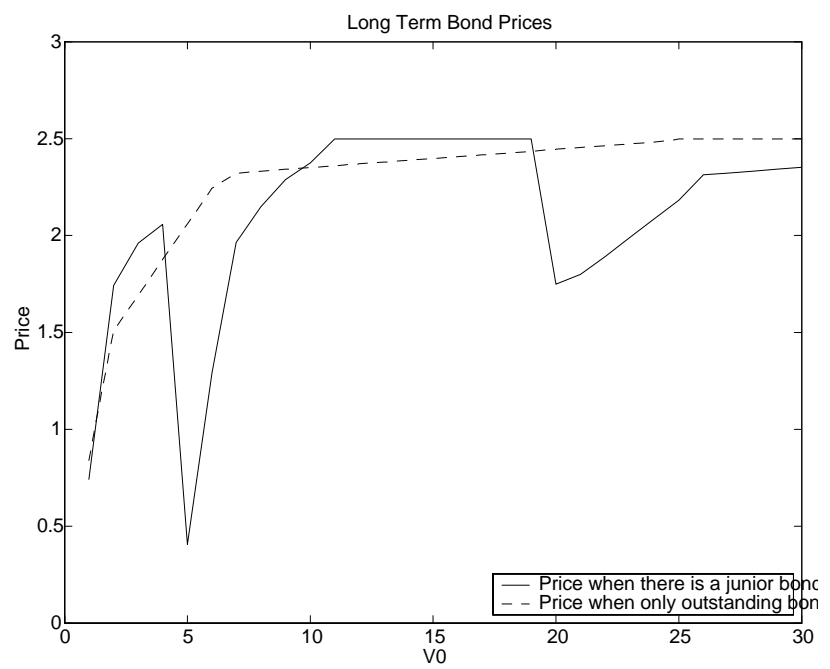

Figure 5: Comparison of the long-term prices in two firms with different capital structure. The values of parameters are: $D_{1}=10, D_{2}=6, K=0.4, L=0.02, p=0.7$, $u=2, d=0.5$

costs are paid, while the owner of the bond $B_{1}^{\prime \prime}$ has to wait also for the senior debt to be paid. So, the price of the bond $B_{1}^{\prime \prime}$ with maturity $t=1$ is strictly lower in the presence of another senior debt (even if this senior debt has later maturity).

We have also compared the price of the long-term bond $B_{2}^{\prime \prime}$ with the price of the bond $B_{2}^{\prime}$. It is quite intuitive that the value of a senior debt is lower or equal in the presence of a junior debt with earlier maturity because the payment done to Bondholder 1 at date 1 decreases the value of the firm, and therefore, may decrease the payment to Bondholder 2 at date 2. However, this does not seem to be always the case. If at date 1 , we have default on the obligation $D_{1}$, we have liquidation and Bondholder 2 receives $\min \left\{V_{1}-L, \frac{D_{2}}{1+r}\right\}$. Assume that the value of the firm is high enough, such that $\min \left\{V_{1}-L, \frac{D_{2}}{1+r}\right\}=\frac{D_{2}}{1+r}$. Consider now what happens with the bond $B_{2}^{\prime}$. If the value of the firm is low enough to give rise to default of the second firm at date 2, the payment to $B_{2}^{\prime}$ is going to be lower than $\frac{D_{2}}{1+r}$ and therefore, the price of the bond $B_{2}^{\prime \prime}$ is going to be higher than the price $B_{2}^{\prime}$. The insight is simple and it is the consequence of the fact that the bond $B_{2}^{\prime \prime}$ is a senior bond. If the value of the firm is low, so it will lead almost surely to default on $B_{2}^{\prime}$ in several states at date 2, Bondholder 2 might be welcoming a liquidation at date 1 which leaves him better off. However, he can be better off by cashing in its payment at date 1 , only if the value of the firm is not too low. The two regions in Figure 5 where the price 
of the senior bond is higher when there exists a short-term bond correspond exactly to this case.

\section{Conclusions}

In this paper we attempt to derive the prices of debt and equity and to analyze the implications of strategic behaviour and capital structure of a firm on the prices of bonds. Our main result is that both strategic behaviour and the capital structure of the firm have important effects on the prices of bonds. To study these implications we set our problem in three different backdrops and we compare the prices we obtain. The whole analysis has been conducted focusing on the determination of the lower reorganization boundary and on the payoffs received by agents. We investigate first the inference of strategic behaviour of the agents on the prices of the bonds. For that we compare the prices of the short-term and long-term bond in two firms with a similar capital structure. The only difference between the two firms lies in the behaviour of the agents in case of default at date 1 , in one setting allowing the agents to step in and restructure the debt. The model allows us also to understand the importance of the covenants of the bonds in the case there are multiple creditors. We conclude that allowing for strategic behaviour of bondholders leads to important changes in prices of bonds. In addition, we obtain an increase in the value of the firm, but this increase takes place only when liquidation and restructuring cost are different from zero. We conclude therefore, that strategic behaviour offsets partially the loss provoked by these costs. However, the strategic behaviour by itself does not lead to any detriment in the value of the firm because it just reallocates the present funds. Thus, when there are no liquidation and restructuring costs, we obtain that the Modigliani-Miller theorem holds.

Secondly, we consider the effect of capital structure of the firm on the prices of bonds. We compare the prices of the short and long-term bond in the previous firm (without strategic behaviour) with the prices of a short and a long-term bond, in a firm where the short-term bond and respectively the long-term bond are the only outstanding debt. It is quite intuitive that the presence of a senior bond decreases the value of a junior bond by comparison with the case when the junior bond is the only bond outstanding. However, we obtain also that the presence of a junior bond with earlier maturity can decrease the price of a senior bond with later maturity. There are two cases when this happens. First case is the one when the value of the firm at date 1 is small and the firm cannot pay out its debt obligations. The firm is defaulting and goes bankrupt. Since bankruptcy involves significant costs, the payments due to the senior bond are 
also endangered. The second case takes place when the firm is not defaulting at date 1 , but the value of the firm is not too high. At date 1 the firm is paying the untitled debt $D_{1}$ and to do that needs to liquidate a part of its assets. Hence, the value of the firm $V_{1}$ decreases by $D_{1}$ and this induces a higher likelihood of default at date 2 on the senior bond.

Simple in essence, our model suggests that the presence of multiple creditors and of a reacher capital structure is an important issue to be considered in pricing corporate debt.

Finally, we mention a possible extension of our work. As has been already pointed out by Anderson, Sundaresan and Tychon (1996), the analysis of strategic contingent claims comes at the cost of a substantial calculation time. To overcome this difficulty they recast the AndersonSundaresan (1996) model in continuous time. Conditional on the success of the remodeling in continuous time, we could proceed in replicating the work of Anderson et al. (1996). As we already mentioned, they compare Merton's model with the one in Anderson and Sundaresan (1996). It will be interesting to make a similar comparison between our model with strategic claims and the one without strategical claims. This last model will be a slightly modified version of Black and Cox (1976), where we have to allow for different maturity dates. However, the task is not trivial in our model because we consider the restructuring of entire debt and therefore we will not be able to use the limit technique used by Anderson et al. (1996).

\section{References}

[1] Anderson, R.W. and T. Cheng, 1998, Numerical Analysis of Strategic Contingent Claims Model, Computational Economics 1, 3-19.

[2] Anderson, R.W. and S. Sundaresan, 1996, Design and Valuation of Debt Contracts, Review of Financial Studies 9, 37-68.

[3] Anderson, R.W. and S. Sundaresan, 2000, A Comparative Study of Structural Models of Corporate Bond Yields: An Exploratory Investigation, Journal of Banking and Finance 24, 255-269.

[4] Anderson, R.W., S. Sundaresan and P. Tychon, 1996, Strategic Analysis of Contingent Claims, European Economic Review 40, 871-881.

[5] Black, F. and J.C. Cox, 1976, Valuing Corporate Security: Some Effects of Bond Indenture Provisions, Journal of Finance 31, 351-367. 
[6] Black, F. and M. Scholes, 1973, The Pricing of Options and Corporate Liabilities, Journal of Political Economy 81(3), 637-659.

[7] Christensen, P.O., C.R. Flor, D.Lando and K. Miltersen, 2002, Dynamic Capital Structure with Callable Debt and Debt Renegotiations, working paper.

[8] Fan, H. and S. Sundaresan, 2000, Debt Valuation, Renegotiation, and Optimal Dividend Policy, Review of Financial Studies 13, 1057-1099.

[9] Franks, J.R. and W.N Torous, 1989, An Empirical Investigation of U.S. Firms in Reorganization, Journal of Finance 44 (3), 747-769.

[10] Fries, S.M., M. Miller, and W.R.M Perraudin, 1997, Debt Pricing in Industry Equilibrium, Review of Financial Studies 10, 39-68.

[11] Gilson, S.C., J. Kose and L.H. Hang, 1990, Troubled Debt Restructurings: An Empirical Study of Private Reorganization of Firms in Default, Journal Financial Economics 27 (2), 315-353.

[12] Kim, I.J., K.Ramaswamy, and S. Sundaresan, 1993, Does Default Risk in Coupons Affect the Valuation of Corporate Bonds?: A Contingent Claims Model, Financial Management, Autumn, 117-131.

[13] Leland, H.E., 1994, Risky Debt, Bond Covenants and Optimal Capital Structure, Journal of Finance 49, 1213-1252.

[14] Leland, H.E. and K.B. Toft, 1996, The Optimal Capital Structure, Endogenous Bankruptcy and the Term Structure of Credit Spreads, Journal of Finance 51, 987-1019.

[15] Mella-Barral, P., 1999, The Dynamics of Default and Debt Reorganization, Review of Financial Studies 12, 535-578.

[16] Mella-Barral, P. and W.R.M. Perraudin, 1997, Strategic Debt Service, Journal of Finance $52,531-556$.

[17] Merton, R.C., 1974, On the Pricing of Corporate Debt: The Risk Structure of Interest Rates, Journal of Finance 29, 449-470. 